\title{
Modeling of Airport Rigid Pavement Structure Made of RCC and Recycled Cement Concrete for Complex Configuration of Landing Gears
}

\author{
Radu Cojocaru ${ }^{1,}$, Jorge C. Pais ${ }^{1, b}$, Radu Andrei ${ }^{1, c}$, Mihai Budescu ${ }^{1, d}$ \\ 1. "Gheorghe Asachi" Technical University of lasi, \\ Faculty of Civil Engineering and Building Service, \\ Dimitrie Mangeron Blvd. no. 43, postal code 700050, Iasi, Romania, \\ 2 "Universidade do Minho" School of Engineering, \\ Campus de Azurém, P-4800-058 Guimarães, Portugal \\ aradu_cojocaru82@yahoo.com; bjpais@civil.uminho.pt; ${ }^{c}$ radu.andrei.d@gmail.com; \\ dmbsinfex@yahoo.com
}

\begin{abstract}
Keywords: airport rigid pavement, complex landing gear, finite elements, design diagrams, recycled materials
\end{abstract}

\begin{abstract}
This paper presents the results of the research undertaken by the authors in the frame of the postdoctoral program 4D-POSTDOC. After a short introduction on the actual status of structural design of airport pavements including geometrical and loading characteristics of complex loading gears, the modeling and the structural design of airport rigid pavements, constructed with conventional and various recycled materials, using the finite element method, is described. The main objective of this research program was to elaborate a design method which, beside the complex landing gear including six footprint tires, all specific parameters related with the recycled materials and with conventional and reinforce rolled compacted concrete (RCC) technologies are included. Finally, practical design diagrams for structural design of the concrete slabs, including their specific correlation function, used for the construction of the Airbus-A380 runway are presented.
\end{abstract}

\section{Introduction}

The evolution of the modern airplanes features (Airbus-A380, Boeing-B777) and also the innovations recording in the field of pavement materials and construction technologies are justifying the actual need to developed new methods and design schemes capable to allow the simulation of complex landing gear's actions, and to consider the specific laws of new pavement materials behaviour.

Usually, the design of concrete slabs for airport runways involves the use of specific diagrams covering various types of landing gears and loads $[1,4]$. Based on based on the maximum tensile stress, the design load and the modulus of subgrade reaction $(\mathrm{k})$ at the upper layer of foundation, the thickness of the concrete slab is finally obtained from these diagrams. From the great variety of the geometric parameters specific for different airplanes, requesting a large number of design diagrams, in our study only the standard the standard landing gears with six tire footprints has been taken into account.

Geometrical and Loading Caracteristics of Complex Landing Gear. As mentioned above, the new diagrams and the interpolation correlations for the commercial aircraft A380-800 with maximum ramp weight of $512 \mathrm{tf}$, having a complex landing gear with six footprint tires (fig.1-body landing gear) [3] are presented. The Airbus A380-800 has been selected for our study, being the most representative aircraft in the investigated category, having the heaviest mass at take-off and the most complex landing gear.

The entire mass of the aircraft it is distributed between the secondary landing gear (noise gear) and the main landing gears (body gears, wing gears) according to position of its gravity center. The big distance between the landings gears justifies taking into accounts separately, every landing 
gear's influence. The design loading is the main landing gear load P determined by the take-off mass of the aircraft. In some cases the secondary landing gear may be the critical one for the airport rigid pavement and therefore simulations for each landing gear must be done. Every type of airport pavement surface (airstrip, taxi runway, road shoulder, platform etc.) has to be distinctly designed according with the different types of loading and the fatigue phenomena due to loading repetition.
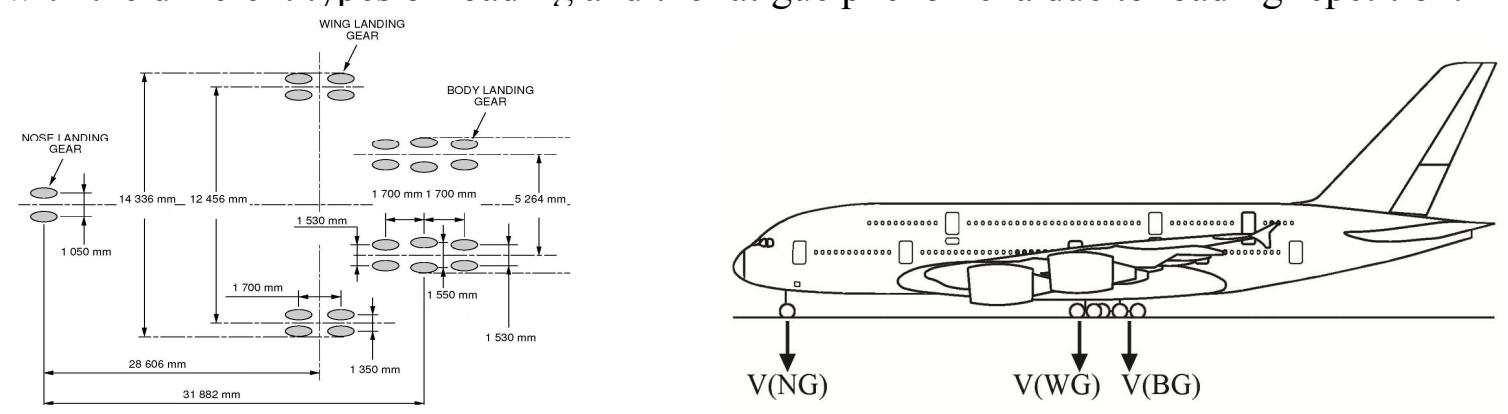

Fig. 1 Landing gear footprint for Airbus A380-800 Fig. 2 Loading scheme for Airbus A380-800

The Determination of the Maximum Stress $\sigma$. One the important design criteria for concrete slabs for airport runways is the maximum tensile stress $\sigma_{t}$ developed at the bottom of the slab under the aircraft loadings.

The values $\sigma_{t}$ from the diagrams have been obtained using computer software ANSYS 11 (U.S.A.). The calculation scheme is made by using three-dimensional finite elements, parallelepiped (Solid - BRICK), with eight nodes and six faces. The concrete slab has been meshed in four layers of finite elements of „brick” type with constant thickness/ height so that a later thickening of the element would not lead to variations of $\sigma_{t}$ stress greater than $0.5 \%$ (Fig. 3). In the impact zone of the landing gear it has been assured a finer mesh with the aim to get the most accurate answer from model. The calculation model is made of cement concrete slab resting on elastic springs whose rigidity is given by the modulus of reaction $\mathbf{k}$. The reaction modulus at the equivalent layer surface it is obtained from diagrams depending on the $\mathrm{k}_{0}$ values (the reaction modulus at ground level) and the equivalent thickness of the subadiacente layers, calculated with a relationship type AASHO Road Test / SBA-STBA $[1,5,6]$.

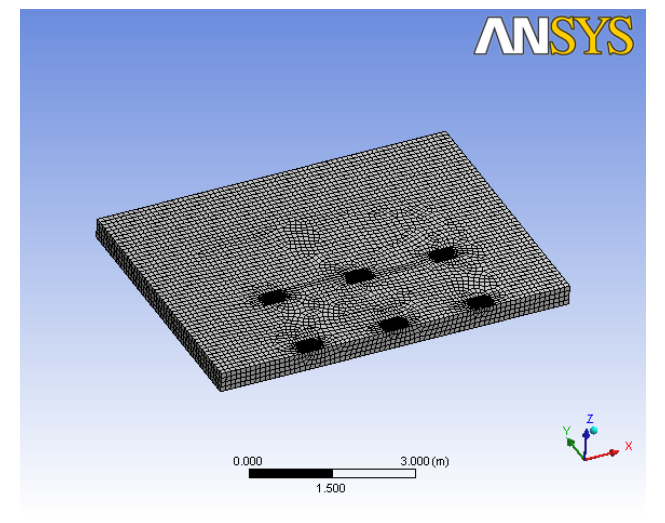

Fig. 3 Finite Element mesh of the slab

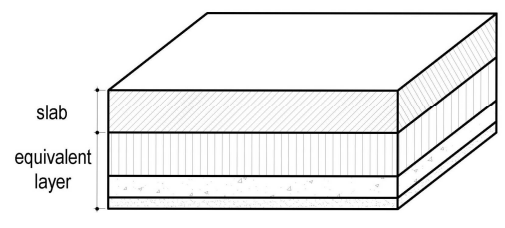

a)

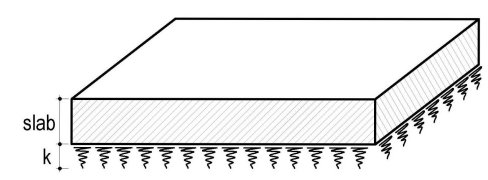

b)

Fig. 4 a) components of rigid pavement strucure; b) computation model

Runway/rigid airport pavements are divided in concrete slabs; between these contractionbending joints the expansion joints are provided. The slab dimensions in plane that were chosen, of $5.00 \times 7.00 \mathrm{~m}$ represent the maximum working width of the concrete casting machine and the maximum length allowed between contraction-bending transverse joints. After several simulations with different dimensions in plane of the concrete slabs, the $5.00 \times 7.00 \mathrm{~m}$ slab generates the maximum covering stress.

The aircraft weights are transmitted to the airport pavement structure in the form of the uniformly distributed load at the contact surface between the tire and the runway track. The size of 
the contact area (A) depends on the vertical gear load (P) and tire pressure (p): $A=P / p$. The loading it is sent thought rectangular footprints, with dimensions: lengtht $L=0.8172 L_{e}$ and width $l=0.6 L$ where $L_{e}{ }^{2}=A / 0.5227$ ( $\mathrm{L}_{\mathrm{e}}-$ length of elliptical tire print) [5,6,].

Researches regarding the influence of loading positions (D1-center of slab, D2-long side tangent to the slab, D3-at the corner of the slab, D4-tangent to contraction-expansion joint) concluded that D2 loading position is the most critical one if the uniform resting of the slab condition is satisfied. In this case the maximum stress it is not influenced by the other aircraft loads because of the contraction-expansion joints. The maximum tensile stresses are being generated by the body gear (compose from six tires) and their values are calculated taking into account only one slab.

Based on the results of these studies, the following parameters have been taking into account for new diagrams: Young modululi: $E_{1}=30000[\mathrm{MPa}], E_{2}=40000[\mathrm{MPa}], \quad E_{3}=50000[\mathrm{MPa}]$; Poisson's ratio: $v_{1}=0.15$; slab dimesions: $L x l=7.00 \times 5.00[\mathrm{~m}]$; reaction modululi $\mathrm{k}: \mathrm{k}_{1}=15\left[\mathrm{MN} / \mathrm{m}^{3}\right]$, $\mathrm{k}_{2}=30\left[\mathrm{MN} / \mathrm{m}^{3}\right], \mathrm{k}_{3}=50\left[\mathrm{MN} / \mathrm{m}^{3}\right], \mathrm{k}_{4}=75\left[\mathrm{MN} / \mathrm{m}^{3}\right], \mathrm{k}_{5}=150\left[\mathrm{MN} / \mathrm{m}^{3}\right]$; the thickness of the concrete slab fluctuates between 20 and $50 \mathrm{~cm}$ with a rate of $10 \mathrm{~cm}$; the dimension of loading area $57 \times 34 \mathrm{~cm}$.

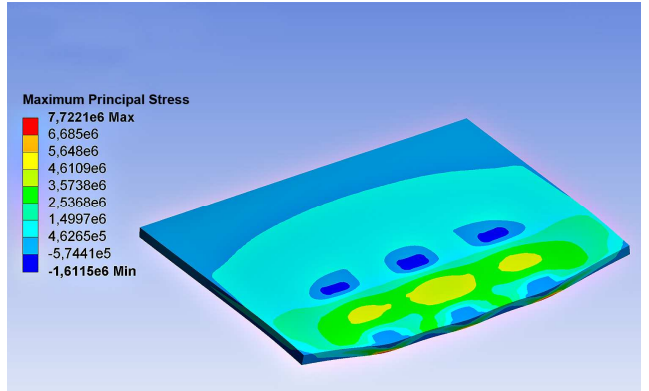

Fig. $5 \sigma_{t}$-deformed in position D2

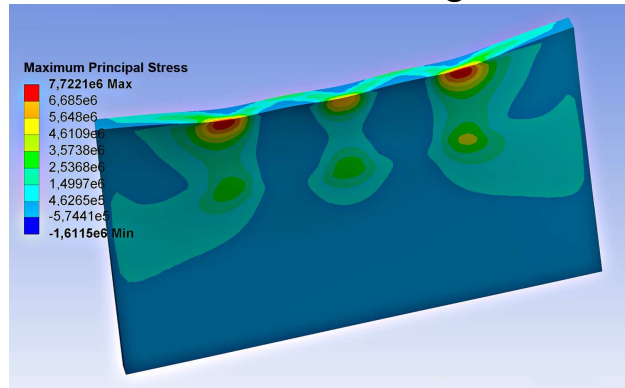

Fig. $6 \sigma_{t}$-deformed in position D2 (base of the slab)

The results from the finite element method have been used to realise the diagrams: $\sigma_{t}=f(K, H)$; $H=f\left(\sigma_{t}, K\right)$ (fig.7). The design diagrams may be used: to find out the thickness of the slab- $H$, or to verify the value of bending tensile stress $\sigma_{t}$, if the other values are known. The Y-coordinate (ordinate) represents for normal scales the values of the concrete for bending tensile stress $\sigma_{t}[\mathrm{MPa}]$, while the X-coordinate (abscissa) represents the thickness of the concrete slab $\mathrm{H}_{\text {slab }}$.
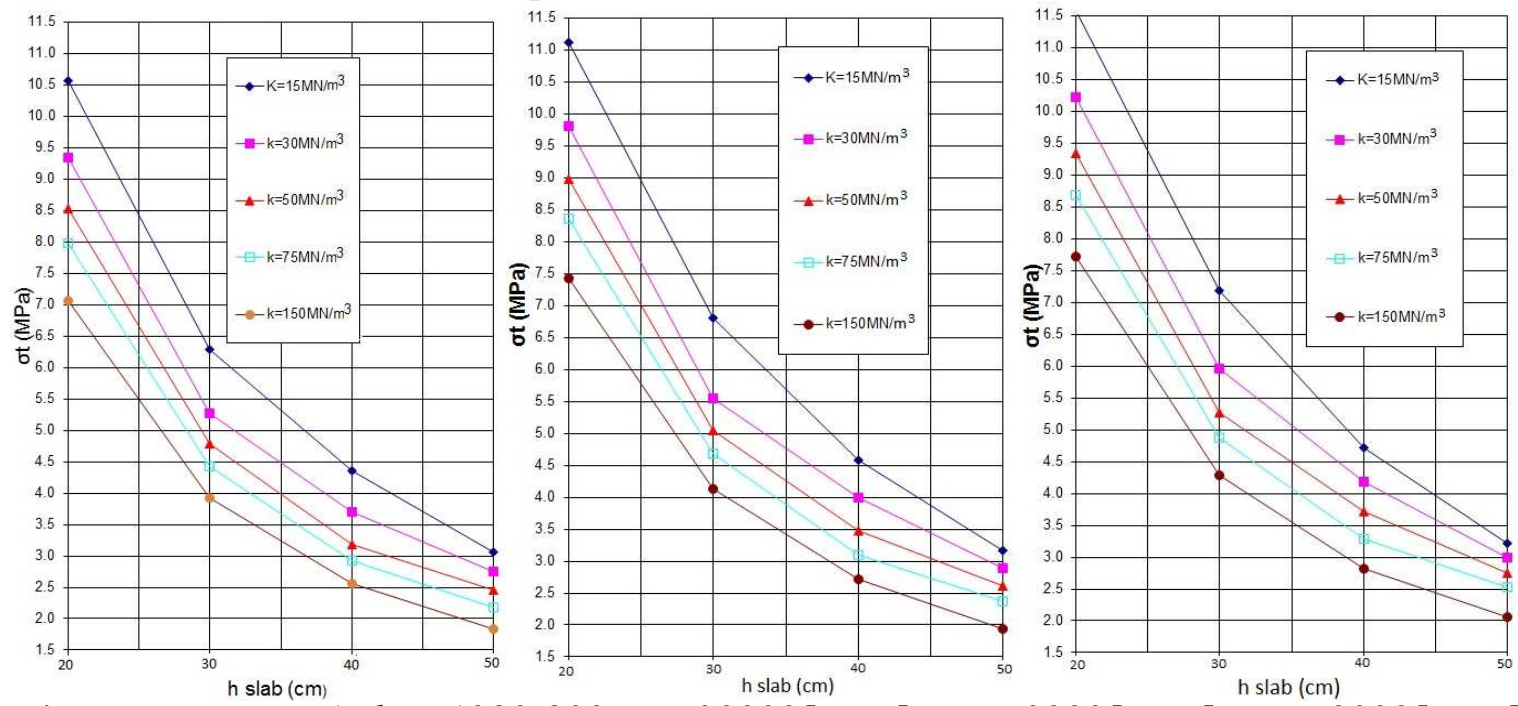

Fig. 7 Diagram - Airbus A380-800, $E_{1}=30000[\mathrm{MPa}], E_{2}=40000[\mathrm{MPa}], E_{3}=50000[\mathrm{MPa}]$

The Correlation Function of the Diagrams. Weibull (1) correlation functions have been used for interpolation in-between values. As shown in figure 8 this function has the smallest errors of interpolation. 


$$
\sigma_{t}=a-b \cdot e^{\left(-c \cdot H^{d}\right)}
$$

(1)

Table 1. The coefficients of interpolation function for one diagram, E-30000[MPa]

\begin{tabular}{|c|c|c|c|c|}
\hline $\mathbf{E}=\mathbf{3 0} 000$ & MPa & \multicolumn{4}{|c|}{ Weibull Model: $\boldsymbol{\sigma t}=\mathbf{a}-\mathbf{b}^{*} \exp \left(-\mathbf{c}^{*} \mathbf{H}^{\wedge} \mathbf{d}\right)$} \\
\hline $\mathrm{K}\left[\mathrm{MN} / \mathrm{m}^{3}\right]$ & $\mathrm{a}$ & $\mathrm{b}$ & $\mathrm{c}$ & $\mathrm{d}$ \\
\hline 15 & 12.34 & 10.48 & 8314.23 & -2.82 \\
\hline 30 & 10.76 & 8.58 & 43242.05 & -3.37 \\
\hline 50 & 10.55 & 8.84 & 13549.56 & -3.05 \\
\hline 75 & 10.19 & 8.81 & 7775.27 & -2.88 \\
\hline 150 & 9.30 & 8.30 & 4306.47 & -2.70 \\
\hline
\end{tabular}

Fig. 8 The graphic for one of interpolation function

Structural Design Criterion. The structural design criterion is expressed by formula: $\sigma_{t} \leq \sigma_{\operatorname{tadm}}$, where $\sigma_{t}$ is the flexural tensile stress at the base slab (are obtained from the design diagrams) and the allowable flexural tensile stress $\sigma_{\text {tadm. }}$. This stress is considered equal to the concrete tensile strength $\mathrm{R}_{\mathrm{ti} 90}$, determined at the age of 90 days, corrected by the safety coefficient $c_{s}: \sigma_{\mathrm{tadm}}=\mathrm{R}_{\mathrm{ti} 90} / \mathrm{c}_{\mathrm{s}}$

The values of the assurance factor: $c_{s}=1.8 \ldots 2.6$, depend on the type of the transfer device used at the joints, as well as the adverse geotechnical, climatic and traffic conditions.

For practical application it was necessary to produce the specific design diagrams in order to obtain the values of $\sigma_{t}$. Values of elasticity modulus E between $30000[\mathrm{MPa}]-50000[\mathrm{MPa}]$, as well the values of Poisson's ratio: $v_{1}=0.15$ (for conventional cement concrete, cement concrete with recycled aggregates and cement concrete reinforcement with steel fibers), $v_{2}=0.25$ (for RCC and RCC reinforcement with steel fibers) [6,7] has to be taken into consideration when using these diagrams.

\section{Conclusions}

1. The main output of this research consists in developing new practical design diagrams for structural design of airport rigid pavements for runways capable to accommodate the modern aircrafts Airbus-A380 and Boeing-B777.

2. This design methodology permits the use of a large spectrum of new conventional and recycled construction materials for the airport runways.

ACKNOWLEDGMENT: This paper was supported by the project "Develop and support multidisciplinary postdoctoral programs in primordial technical areas of national strategy of the research - development - innovation" 4D-POSTDOC, contract nr. POSDRU/89/1.5/S/52603, project co-funded from European Social Fund through Sectorial Operational Program Human Resources 2007-2013.

\section{References}

[1] Abdo J., "Chaussees aeronautiques en beton hydraulique. Guide tehnique pour la construction des chaaussees aeronautiques neuves en beton hydrauliques " LCPC, STBA, 2000

[2] G. Griffiths, N. Thom, "Concrete Pavement Design Guidance Notes" New York 2007

[3] Navneet G., - Concrete Airfield Pavement Design - Using FAARFIELD for Rigid Overlays, Concrete Airport Pavement Workshop Atlanta, Georgia, 2009

[4] Zarojanu H. Gh., Bulgaru G. D., "Aeroporturi", Iasi, 2010

[5] Zarojanu H. Gh., Ciongradi I., Budescu M., Rosca O., " Finite element Modeling of the reinforced Airport Slabs" Vol. Proceedings of the 5th International Conference on Boundary and Finite Element, Oradea, 2000.

[6] Andrei R., Taranu N.,Cojocaru R., - Numerical analysis and parametric study of SFRC pavements subjected to traffic, EcoLanes FP6 Project, 2009.

[7] Andrei R., Taranu N.,Cojocaru R., - Algorithms and software for the design of SFRC pavements, EcoLanes FP6 Project, 2009. 